\title{
Potential Impacts of Climate Change on Food Security
}

\author{
Nathan Akila Loks ${ }^{1}$, Abati Mohammed Umar ${ }^{3}$, Domchang Mamzing ${ }^{1}$, Lydia Kachollom Akila² and Cicelia Nyazi \\ Majak $^{2}$ \\ 1. Department of Agricultural Technology, College of Agriculture, Garkawa, Jos City 930001, Plateau State, Nigeria \\ 2. Department of Home and Rural Economics, College of Agriculture, Garkawa, Jos City 930001, Plateau State, Nigeria \\ 3. Department of Soil Science, Faculty of Agriculture, Bayero University, Kano City 700002, Kano State, Nigeria
}

\begin{abstract}
In view of the fact that climate-related disasters are already taking a heavy toll, causing massive damage to crops and infrastructure and forcing some people to flee their homes, however, the potential impacts of climate change are likely to trigger adaptive responses that influence environmental and socio-economic drivers of food system performance in positive as well as negative ways. This paper was conducted through the collection of some research materials with the projected balance of these various climate impacts on food system performance and food security outcomes at the local and global levels. More so that, food security is likely to be affected by climate change in several ways: food security depends not only on the direct impact of climate change on food production but also on its indirect impact on human nutrition and health, economic growth, trade flows and food aid policy. The paper further examined the effectiveness of managing new risks and uncertainty, improving the quality of information and its use, monitoring weather and improving scientific understanding of climate change, promoting insurance schemes, maintaining biodiversity and access to fund as some of the crucial measures for adaptation. The large amount of resources that would be necessary to avoid the worst case scenario suggests the necessity of continued support from the international community to improve food security at the local and global levels as a whole.
\end{abstract}

Key words: Climate change, food security, food system, food availability, food affordability.

\section{Introduction}

Until about 200 years ago, climate was a determinant for food security. Since the advent of the food revolution, however, humanity's ability to control the forces of nature and manage its own environment has grown enormously. Climate is the average weather condition in a given place, usually over a period of 30 years. Climate has natural year to year variations, and extremes in temperatures and weather events have occurred throughout history [1]. There is also anthropogenic climate change, which simply refers to human-induced global warming and the associated changes in climate. Nellemann et al. [2] stated that climate change is considered to pose the greatest threat to agricultural production and food security in the 21st century, particularly in many of the poor, agriculture-based countries of Sub-Saharan

Corresponding author: Nathan Akila Loks, Ph.D. student, research field: agronomy.
Africa, due to their low capacity to effectively cope with a possible decrease in yields among others.

As adopted at the World Food Summit (WFS) [3], "food security exists when all people at all times have physical or economic access to sufficient safe and nutritious food to meet their dietary needs and food preferences for an active and healthy life”.

According to FAO [4], mean global temperatures have been increasing since about 1850, mainly owing to the accumulation of greenhouse gases in the atmosphere. The main causes are the burning of fossil fuels (coal, oil and gas) to meet increasing energy demand and the spread of intensive agriculture to meet increasing food demand, which is often accompanied by deforestation, and the process of global warming shows no signs of abating and is expected to bring about long term changes in weather conditions. Therefore, these changes will have serious imparts on the four dimensions of food security: food availability, 
food accessibility, food utilization and food system stability, and they are already being felt in global food markets and likely to be particularly significant in specific rural locations where crop fails and yield decline. Impacts are felt in both rural and urban locations, where supply chains are disrupted, market prices increase, assets and livelihood opportunities are lost, purchasing power fails, human health is endangered and affected people are unable to cope.

The study has sole objective of examining critically how local and global food security is responding to the uncertainties of climate change and the adaptation measures that can help deal with such uncertainties.

\section{Materials and Methods}

The paper has reviewed relevant literatures on the potential impacts of climate change on food security, including the following: World Food Summit (WFS) [3], Climate-Smart Agriculture Policy and Financing for Food Security, Adaptation and Mitigation, FAO [5], Food Insecurity and Vulnerability Information and Mapping System (FIVIMS) [6], International Labour Organisation (ILO) [7], Climate Change and Food Security [8], Intergovernmental Panel on Climate Change (IPCC) [9], Global Environmental Facility (GEF) [10], United Nations Framework Convention on Climate Change (UNFCCC) [11] and Least Development Countries Fund (LDCF) [10].

The approaches adopted were analytic descriptive and explorative, which were used at the same time. This paper examined how climate change could affect projections for agricultural production and food security in the 21st century. As well, the paper further examined the four dimensions of food security, including: food availability, stability of food supplies, access to food and food utilization, which are likely to be affected by climate change. In the analysis, the paper focused on food preferences, food utilization and food emergencies. The agricultural production was linked with broader socio-economic-environmental processes in order to depict adaptation to climate change and food security. Also, the paper further accessed how projections for key food security indicators, such as agriculture production and rural poverty, were affected by the uncertainty in climate change, and how investment in adaptation measures can help deal with such uncertainties. In addition, the paper investigated some policy options, such as promoting insurance schemes for climate change risk, access for funds, creating an eco-friendly energy economy and maintaining biodiversity as some of the adaptation measures.

\section{Results and Discussion}

Though climate change may benefit agriculture and food production somewhat in a small number of places, overwhelmingly the reports coming out on increasing temperatures, ocean acidification and changing precipitation patterns show that in the vast majority of places, the impact will be negative, if not always catastrophic. A quick Tree Hunger archive review reveals:

(1) Asian rice yields dropped $10 \%$ for every $1{ }^{\circ} \mathrm{C}$ increase in daily minimum temperatures;

(2) Corn cotton and soybean yields in the United States declined 30\%-40\% under slow global warming scenarios and $63 \%-82 \%$ under rapid warming;

(3) Coral reef loss in Southeast Asia reduced food production up to $80 \%$ in the region, due to ocean acidification.

\subsection{Conceptualizing Relationships}

\subsubsection{Food Systems and Food Security}

\subsubsection{Food Security}

In May 2007, at the 23rd session of the committee on World Food Security, FAO issued a statement to reaffirm its visitation of a food-secure world: "FAO's vision of a world without hunger is one, in which most people are able, by themselves, to obtain the food they need for an active and healthy life, and where social safety net ensure that those who lack resources still get enough to eat” [12]. 
According to Schmidhuber and Jubiello [13], food security could be defined as "a situation when all people at all times, have physical, social and economic access to sufficient, safe and nutritious food that meets their dietary needs and food preferences for an active and healthy life”. FAO [14] stated that food security is not narrowly defined as whether food is available, but in addition, whether the monetary and the non-monetary resources at the disposal of the population are sufficient to allow everyone access to adequate quantities and qualities of food. More specifically, the four dimensions of food security include food availability, stability of food supplies, access to food and food utilization. All these dimensions of food security are likely to be affected by the climate change.

\subsubsection{Food System}

Between 1990 and 2003, a series of expert consultations convened by the Global Environmental Change and Food System Project with FAO's participation, developed a version of the food insecurity and vulnerability information and mapping system (FIVIMS), which further clarifies how a variety of processes along a food chain need to occur in order to bring about food security. Taken together, these processes constitute the food system, and the performance of food system determines whether or not food security is achieved. Therefore, food system encompasses the following: (1) activities related to the production, processing, distribution, preparation and consumption of food and (2) the outcomes of these activities contributing to food security (food availability with elements related to production, distribution and ex-change, food access with elements related to affordability, allocation and preference, and food use with elements related to nutritional value, social value and food safety). The outcomes also contribute to environmental and other securities (e.g., income). Interactions between and within bio-geophysical and human environments influence both the activities and the outcomes [15]. Another study expresses the complexity of food systems and their link to food security as follows: diagrammatic interactions between and within the bio-geophysical and human environments lead to the production process, preparation and consumption of food, resulting in food system that underpin food security [8].

\subsubsection{Climate and Climate Change}

Climate refers to the characteristic conditions of the earth's lower surface atmosphere at a specific location. Weather refers to the day to day fluctuations in these conditions at the same location. The variables that are commonly used by meteorologists to measure daily weather phenomena are air, temperature, precipitation (e.g., rain, sleet, snow and hail), atmospheric pressure and humidity, wind and sunshine and cloud cover. When these weather phenomena are measured systematically at a specific location over several years, a record of observation is accumulated, from which averages, ranges, maximums and minimums for each variable can be computed, along with the frequency and duration of more extreme events.

Climate change is a significant and lasting change in the statistical distribution of weather patterns over periods ranging from decades to millions of years [16]. It may be a change in weather conditions or in the distribution of weather around the average conditions, e.g., extreme weather events. Climate change, in the most general sense, encompasses all forms of climate inconstancy (i.e., any differences from long term statistics of the meteorological elements calculated for different periods but relating to the same area), regardless of their statistical nature or physical causes. Climate changes may result from factors, such as changes in solar emission, long term changes in the earth's orbital elements (eccentricity, obliquity of the ecliptic, precessions of the equinoxes), natural internal processes of the climatic system, or anthropogenic forcing (e.g., increasing atmospheric concentrations of $\mathrm{CO}_{2}$ and other greenhouse gases). The term is used in a more restricted sense to denote a significant change 
(i.e., a change with important economic, environmental and social effects) in the mean value of a meteorological element (particularly temperature or amount of precipitation) in the course of a certain period, where the means are taken over periods of a decade or longer [17].

\subsubsection{Climate Change and Food Security}

Climate change is considered to pose the greatest threat to agriculture production and food security in the 21st century, particularly in many agriculture-based countries, due to their low capacity to effectively cope with possible decrease in yields among others [18]. Agriculture is important for food security in two ways: (1) it produces the food people eat and (2) provides the primary source of livelihood for $36 \%$ of the world's total workforce (perhaps even more important). In the heavily populated countries of Asia and the Pacific, this share ranges from $40 \%$ to $50 \%$, and in Sub-Saharan Africa, two-thirds of the working population still make their living from agriculture [7]. If agricultural production in the low income developing countries of Asia and Africa is adversely affected by climate change, the livelihood of large numbers of the rural poor will be put at risk and their vulnerability to food insecurity increases.

Food systems exist in the biosphere, along with all other manifestations of human activity. Some of the significant changes in the biosphere that are expected to result from global warming, will occur in the more distant future, as a consequence in changes in average weather conditions. The most likely scenarios of climate change that increases in weather variability and the incidence of extreme weather events will be particularly significant now and in the immediate future. The projected increases in mean temperatures and precipitation will not manifest through constant gradual changes, but will instead be experienced as increased frequency, duration and intensity of hot spells and precipitation events. Whereas the annual occurrence of hot days and the maximum temperatures are expected to increase to be uniformly distributed around the world. In general, it is projected that wet regions will become wetter and dry regions dryer. Fig. 1 shows how climate change affects food security (food availability, food accessibility, food utilization and food system stability) in various direct and indirect ways. Climate change variables influence biophysical factors, such as plant and animal growth, water cycles, biodiversity and nutrient cycling and the ways in which these are managed through agricultural practices and land use for food production. However, climate variables also have impacts on physical/human capital, such as roads, storage and marketing infrastructure, houses, productive assets, electricity grids and human health which directly changes the economic and socio-political factors that govern food access and utilization and can threaten the stability of food systems. All these impacts manifest themselves in the way, in which food systems activities are carried out. The framework illustrates how adaptive adjustments to food system activities will be needed all along the food chain to cope with impacts of climate change. The climate change variables considered in the climate change and food security (CCFS) framework are:

(1) The $\mathrm{CO}_{2}$ fertilizer effect of increased greenhouse gases concentration in the atmosphere;

(2) Increasing mean, maximum and minimum temperatures;

(3) Gradual change in precipitation;

(4) Increase in the frequency and the intensity of storms and floods;

(5) Greater seasonal weather variability and changes in the start/end of growing seasons.

\subsection{Vulnerability to Climate Change}

Risk exists when there is uncertainty about the future outcomes of ongoing processes or about the occurrence of future events. The more certain an outcome is, the less risk there is, because certainty allows informed choices and preparations to deal with the impacts of hazardous processes or events. 


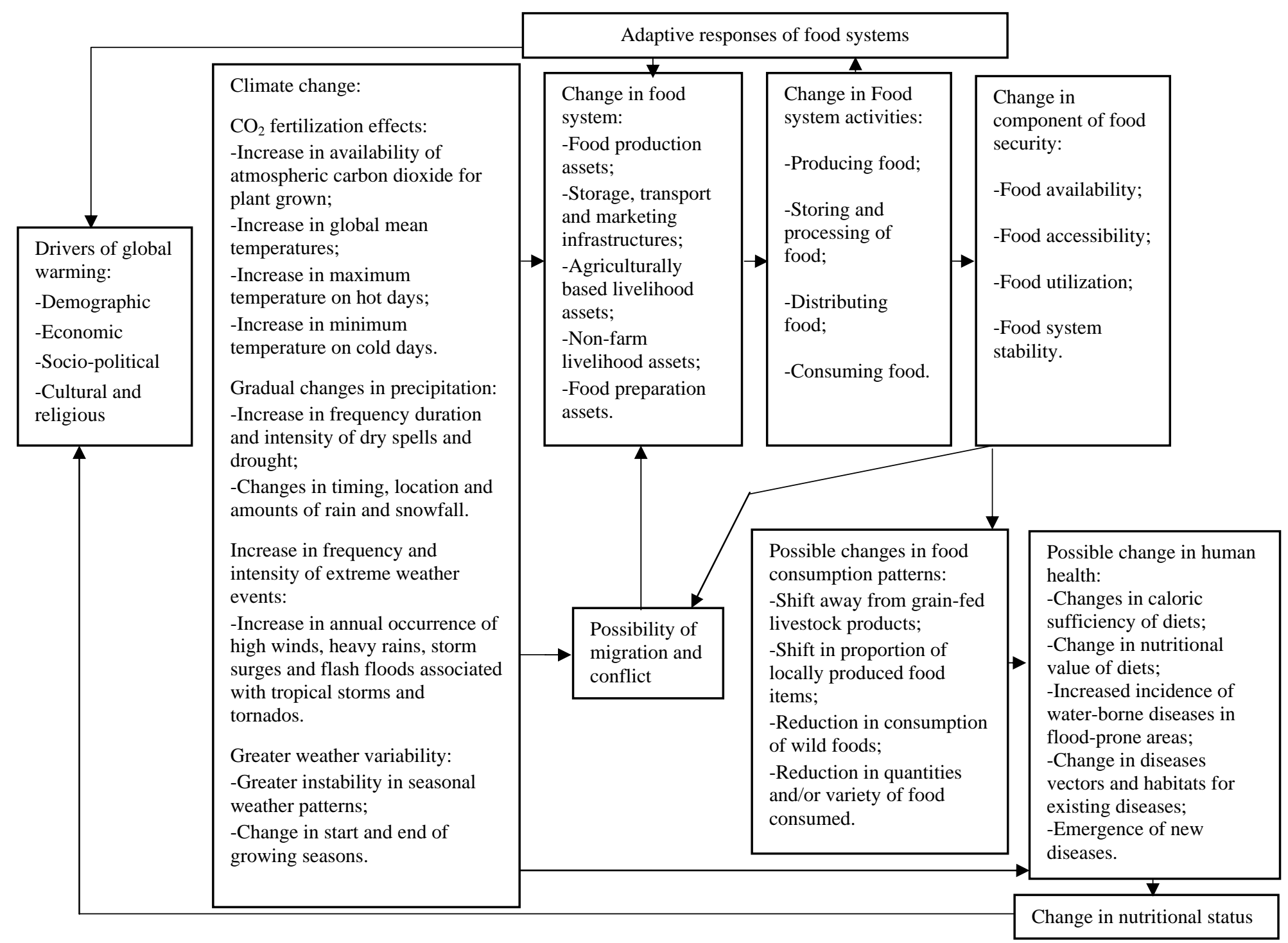

Fig. 1 Climate change and food security.

Source: FAO/NRCB 2008 [19]. 
Global climate change projections have a solid scientific basis and there is a growing certainty that extreme weather events are going to increase in frequency and intensity. This makes it highly likely that asset losses attributable to weather related disasters will increase. Whether these losses involve productive assets, personal possessions or even loss of life, the livelihoods and food security status of millions of people in disaster prone areas will be adversely affected. An average of 500 weather related disasters are now taking place each year, compared with 120 in the 1980s, and the number of floods has increased six fold over the same period [20]. Population increases, especially in coastal areas, when most of the world's population now lives, meaning that more and more people will be affected by catastrophic weather events.

\subsection{Food System Vulnerability}

This occurs when there is uncertain and insecure food availability, food accessibility, food utilization and food stability.

Food availability is determined by the physical quantities of food that are produced, stored, processed, distributed and exchanged.

Food accessibility is the measure of the ability to secure entitlements, which are defined as the set of resources (including legal, political, economic and social), that an individual requires to obtain access to food [21]. Until the 1970s, food security was linked mainly to national food production and global trade [22], but since then, the concept has expanded to include households' and individuals' access to food. The mere presence of an adequate supply does not ensure that a person can obtain and consume food, so that person must first have access to the food through his/her entitlements. Therefore, increased risk exposure resulting from climate change will reduce people's access to entitlements and determine their food security.

Food utilization refers to the use of food and how a person is able to secure essential nutrients from the food consumed. It encompasses the nutritional value of the diet, including its composition and methods of preparation. Climatic conditions are likely to bring both negative and positive changes in dietary patterns and new challenges for food safety, which may affect nutritional status in various ways.

Food system stability is determined by the temporal availability of food and access to food. In long distance food chains, storage, processing, distribution and marketing processes contain in-built mechanisms that have protected the global food system from instability in recent times.

\subsection{Impacts of Climate Change}

3.4.1 Potential Impacts of Climate Change on Food Availability

Production of food and other agricultural commodities may keep pace with aggregate demand, but there are likely to be significant changes in local cropping patterns and farming practices. There has been a lot of research on the impacts that climate change might have on agricultural production, particularly cultivated crops. The evaluation of climate change impacts on agricultural production, food supply and agriculture-based livelihoods must take into account the characteristics of the agro-ecosystem, where particular climate-induced changes in biochemical processes are occurring, in order to determine the extent, to which such changes will be positive, negative or neutral in their effects. For climate variables, such as rainfall, soil moisture, temperature and radiation, crops have thresholds, beyond which growth and yield are compromised [23], For example, cereals and fruit trees yield can be damaged by a few days of temperatures above or below a certain threshold [24]. In European heat wave of 2003, when temperatures were $6{ }^{\circ} \mathrm{C}$ above long term means, crop yield dropped significantly, by $36 \%$ for maize in Italy, and 25\% for fruits and 30\% for forage in France [25]. According to Gleick [26], 
constraints on water availability are growing concerns, which climate change will exacerbate. Conflicts over water resources will have implications for both food production and people's access to food in conflict zones. Prolonged and repeated droughts can cause loss of productive assets, which undermines the sustainability of livelihood system based on rainfed agriculture. In Africa, droughts can have severe impacts on livestock. Table 1 illustrates how droughts increased livestock mortality in selected Africa countries between 1980 and 1999. FAO projects about the impact of climate change on global crop production will be slight up to 2030. After that year, however, widespread decline in the extent and potential productivity of crop land would occur, with some of the severest impacts likely to be felt in the currently food insecure areas of Sub-Saharan Africa, which has the least ability to adapt to climate change or to compensate through greater food imports [27].

3.4.2 Potential Impacts of Climate Change on Food Access

\subsubsection{Allocation}

Food is allocated through markets and non-market distribution mechanisms. Factors that will determine whether people will have access to sufficient food through markets are considered on affordability. These factors include income generating capacity, amount of remuneration received for products and goods sold or labour and services rendered and the ratio of a cost of the minimum daily food basket to the daily average income. Political and social power relationship is a key factor influencing allocation decisions in times of security. If agricultural production declines and households find alternative livelihood activities, social processes and reciprocal relations in which locally produced food is given to other family members in exchange for their support, may change or disappear altogether. Public and charitable food distribution schemes reallocate food to the most needy, but are subject to public perception about who needs help and social values about what kind of help it is incumbent on by more wealthy segments of society to provide. Therefore, if climate change creates other more urgent claims on public resources, support for food distribution schemes may decline, with consequent increases in the incidence of food insecurity, hunger and famine-related deaths.

\subsubsection{Affordability}

In many countries, the ratio of the cost of a minimum daily food basket to the average daily income is used as a measure of poverty [28]. When the ratio falls below a certain threshold, it signifies that food is affordable and people are not impoverished. When it exceeds the established threshold, food is not affordable and people are having difficulty obtaining enough to eat. This criterion is an indicator of chronic poverty, and can also be used to determine when people have fallen into temporary food insecurity, owing to reduced food supply and increased prices to a sudden fall in household income or to both.

Table 1 Impacts of droughts on livestock numbers in selected African countries in 1981-1999.

\begin{tabular}{llll}
\hline Date & Location & Livestock losses & Source \\
\hline $1981-1984$ & Botswana & $20 \%$ of national herd & {$[29]$} \\
$1982-1984$ & Niger & $62 \%$ of national cattle herd & {$[30]$} \\
$1983-1984$ & Ethiopia (Borana Plateau) & $45 \%-90 \%$ of calves, 45\% of cows, 22\% of mature males & {$[31]$} \\
1991 & Northern Kenya & $28 \%$ of cattle, 18\% of sheep and goats & {$[32]$} \\
$1991-1993$ & Ethiopia (Borana) & $42 \%$ of cattle & {$[33]$} \\
1993 & Namibia & $22 \%$ of cattle, 41\% of goats and sheep & {$[34]$} \\
$1995-1997$ & Greater Horn of Africa (average of nine pastoral areas) & $20 \%$ of cattle, 20\% of sheep and goats & {$[35]$} \\
$1995-1997$ & Southern Ethiopia & $46 \%$ of cattle, 41\% of sheep and goats & [35] \\
$1998-1999$ & Ethiopia (Borana) & $62 \%$ of cattle & [33] \\
\hline
\end{tabular}

Source: IPCC 2007 [25]. 
Most food is not produced by individual households, but acquired through buying, trading and borrowing [6]. Climate impacts on income-earning opportunities can affect the ability to buy food, and a change in climate or climate extremes may affect the availability of certain food products, which may influence their price. High prices may make certain foods unaffordable and can have an impact on individuals' nutrition and health.

\subsubsection{Preference}

Food preferences determine which kind of food households will attempt to obtain. Changing climate conditions may affect both the physical and the economic availability of certain preferred food items, which might make it impossible to meet some preferences. Changes in availability and relative prices for major food items may result in people either changing their basket or spending a greater percentage of their income on food when prices of preferred food items increase. In South Africa, for example, many households eat maize as the staple crop, but when there is less rainfall, sorghum fares better and people could consume more of it. Many people prefer maize to sorghum, however, some continue to plant maize despite poor yields and would rather buy maize than eat sorghum, when necessary [27].

3.4.3 Potential Impacts of Climate Change on Food Utilization

Food insecurity is usually associated with malnutrition, because the diets of people who are unable to satisfy all of their food needs usually contain a high proportion of staple foods and lack the variety needed to satisfy nutritional requirements. Declines in the availability of wild foods and limits on small scale horticultural production due to scarcity of water or labour resulting from climate change could affect nutritional status adversely. In general, however, the main impact of climate change on nutrition is likely to be felt indirectly, through its effects on income and capacity to purchase a diversity of foods. The physiological utilization of foods consumed also affects nutritional status, and this in turn is affected by illness. Climate change will cause new patterns of pests and diseases to emerge, affecting plants, animals and humans and posing new risks for food security, food safety and human health. Increased incidence of water-borne diseases in flood-prone areas, changes in vectors for climate-responsive pests and diseases and emergence of new diseases could affect both the food chain and people's physiological capacity to obtain necessary nutrients from the foods consumed. Vector changes are a virtual certainty for pests and diseases that flourish only at specific temperatures and under specific humidity and irrigation management regimes. These will expose crops, livestock, fish and humans to new risks, to which they have not yet adopted. They will also place new pressures on care givers within the home, who are women and will challenge health care institutions to respond to new parameters. Malaria in particular is expected to change its distribution as a result of climate change [25].

3.4.4 Potential Impacts of Climate Change on Food System Stability

\subsubsection{Stability of Food Supply}

Many crops have annual cycles and yields fluctuate with climate variability, particularly rainfall and temperature. Maintaining the continuity of food supply when production is seasonal, is therefore challenging. Droughts and floods are a particular threat to food stability and could bring about both chronic and transitory food insecurity. Both are expected to become more frequent, more intense and less predictable as a consequence of climate change. Changes in the amount and timing of rainfall within the season and an increase in weather variability are likely to aggravate the precariousness of local food systems.

\subsubsection{Stability of Access}

As already noted, the affordability of food is determined by the relationship between household income and the cost of a typical food basket. Global food markets may exhibit greater price volatility, 
jeopardizing the stability of returns to farmers and the access to purchase food of both farming and non-farming poor people.

\subsubsection{Food Emergencies}

Increasing instability of supply, attributable to the consequences of climate change, will most likely lead to increases in the frequencies and magnitude of food emergencies, with which the global food system is ill-equipped to cope. An increase in human conflict, caused in part by migration and resource competition attributable to change climate conditions, would also be destabilizing for food systems at all levels.

3.4.5 Adaptation to Climate Change and Food Security

Intergovernmental Panel on Climate Change (IPCC) [9] defines adaptation as "adjustment in natural or human systems in response to actual or expected climatic stimuli or their effects, which moderates harm or exploits beneficial opportunities". It involves learning to manage new risks and strengthening resilience in the face of change. Risk management focuses on preparing to deal with shocks. Change management focuses on modifying behaviours over the medium to long term to avoid disruptions or declines in global and local food supplies due to changes in temperature and precipitation regimes, and to protect ecosystems through providing environmental services. The following processes for adapting to climate change in the food in the agricultural sector are:

(1) Protecting local food supplies, assets and livelihoods against the effects of increasing weather variability and increased frequency and intensity of extreme events through:

- general risk management;

- research and dissemination of crop varieties and breeds adapted to changing climatic conditions;

- introducing tree crops to provide food, fodder and energy and enhance cash incomes.

(2) Avoiding disruptions or declines in global and local food supplies due to changes in temperature and precipitation regimes through:

- use of new, more energy-efficient technologies by agro-industries;

- improved management of cultivated land;

- improved livestock management;

- more efficient agricultural water management in general.

(3) Protecting ecosystems, through provision of such environmental services as:

- use of degraded or marginal lands for productive planted forests or other cellulose biomass for alternative fuels;

- watershed protection;

- prevention of land degradation;

- biodiversity conservation;

- preservation of mangroves and their contribution to coastal fisheries.

\subsubsection{Managing New Risks and Uncertainty}

Adapting to climate change involves managing risk by improving the quality of information and its use, providing insurance against climate change risk, adapting known good practices to strengthen the resilience of vulnerable livelihood systems and finding new institutional and technological solutions. People in the insurance business make a clear between certain and uncertain risks. A risk is specific, if the probability of specific states occurring in the future is precisely known, and uncertain if these probabilities are not precisely known [36].

3.4.5.2 Improving the Quality of Information and Its Use

Information is a crucial tool in decision-making, particularly in the context of climate change where there is high uncertainty. The type of information, its source(s) to whom it is targeted and how it is to be used, are important elements in determining the impacts and response that information may generate. Good information about uncertainties and risks can make the difference between resilience and collapse for an affected livelihood system or ecosystem, as in the case of climate change. 
3.4.5.3 Monitoring Weather and Improving Scientific Understanding of Climate Change

Scientific works in response to the challenge of climate change include development of tools and technologies for improved monitoring of weather and climate, incorporation of climate change variable and assessments into food security information and early warning systems, observation and modeling of climate impacts on rural livelihoods. As already noted, it is critical that information generated by early warning systems and climate change models should be packaged in a way that is accessible to vulnerable people, so it can assist them in making sound choices about how to adapt to climate change and other stressors. All actors in food system need access to reliable information about climate change and its potential impacts, to avoid breakdowns in the system and adverse food security outcomes.

3.4.5.4 Promoting Insurance Schemes for Climate Change Risk

In 2007, the World Economic Forum [37] outlined the five core areas of global risk as economic, environmental, geopolitical, societal and technological. Within these, climate change is seen as one of the major challenges for the 21st century, as it is a global risk with impacts far beyond the environment. The insurance industry is among the economic sectors that are already experiencing adverse impacts of climate change. Wealthy countries depend heavily on the private insurance industry to protect their citizens against natural disasters. According to Hamilton [38], these countries account for 93\% of the global insurance market. Some of the typical forms of insurance coverage for weather and climate-related events are: floods, windstorm, thunder storms, ice storms, wild fires, droughts, heat waves, lightning strikes, subsidence damage and coastal erosion. It also includes coverage for property damage, business interruptions and loss of life or limb.

\subsubsection{Maintaining Biodiversity}

For local adaptation and resilience, promoting agro-biodiversity is important. Biodiversity in all its manifestations, such as genes, species, ecosystems, increases resilience to changing environmental conditions and stresses. The use of indigenous and locally adapted plant and animal diversity, and the selection and multiplication of crop varieties and autochthonous races that are adapted or resistant to adverse conditions, are encouraged by FAO. Effective use of genetic resources can reduce negative effects of climate change on agricultural production and farmers' livelihoods. Breeding plants and animals for tolerance to drought, heat stress, salinity and flooding will also become important.

\subsubsection{Creating an Eco-friendly Energy Economy}

Meeting the demand for bio-energy should not undermine food security. The demand has been increasing because of the rising cost of petroleum, concern about dependence on fossil fuel imports, the climate change mitigation benefits of reducing reliance on fossil fuels and the increase in demand for fuel wood and charcoal for expanding populations in many parts of the developing world. This explores the intersections among climate change, energy security and food security, and the prospects for second generation bio-fuels and increased energy efficiency as alternatives to bio-fuel crops. Another important issue is the role of sustainability, managed forests and trees as a source of energy at the national and household levels.

\subsubsection{Access to Funds}

Several funds within the United Nations system finance activities aimed at reducing greenhouse gas emissions and increasing resilience to the negative impacts of climate change. The Global Environmental Facility (GEF) was established in 1991 as an independent financial organization providing grants to developing countries for projects that are of benefit to global environment and promote sustainable livelihood in local communities.

In its role as a financing mechanism of United Nations Framework Convention on Climate Change 
(UNFCCC), GEF support mitigation and adaptation measures that generate global benefits through the GEF trust fund. GEF projects on climate change help developing countries and economies in transition to contribute to the overall objective of UNFCCC by reducing or avoiding greenhouse gas emissions in the area of renewable energy, energy efficiency and sustainable transport and by supporting interventions that increase resilience to the adverse impacts of climate change in vulnerable countries, sectors and communities, According to UNFCCC [11], the GEF secretariat administers two funds that focus on developing the Special Climate Change Fund (SCCF) and the Least Development Countries' Fund (LDCF) and will administer the start-up of the adaptation fund, which will has only just become operational.

\section{Conclusions}

There can no longer be any doubt that the earth's climate is changing and this is just the beginning. Everyone is going to feel the consequences. Action is crucial, if the world's future is to be secured. In analysis, this paper illustrates that in order to understand the full range of implications that this phenomenon has for food security, it is important to consider the linkages between expected direct impacts of climate change on agricultural production, food availability, food accessibility, food utilization, food system stability, socio-economic and environmental processes. The combination of a reduction in food production and income for the rural population indicates that the impact of climate on this population might thus be severe. Therefore, measures must be taken to reduce the impact of climate change on the society. Finally, it is believed that the approaches in the paper compliment well the existing approaches to assess the effect of climate change on food security, enhancing the awareness of policy makers of the constraints to the world's adaptive potential. Further research is required to improve this approach and test it in other settings.

\section{Acknowledgments}

The authors are most grateful to God for the wonderful privilege of working together as a team despite the differences in fields of discipline. They also specially thank their husbands, wives and children for their love, prayers, encouragement and moral support in the course of this work.

\section{References}

[1] Pedercini, M., and Barney, G. O. 2010. "Dynamic Analysis of Interventions Designed to Achieve Millennium Development Goals (MDG): The Case of Ghana.” Socio-Economic Planning Sciences 44 (2): 89-99.

[2] Nellemann, C., MacDevette, M., Manders, T., Eickhout, B., Svihus, B., Prins, A. G., and Kaltenborn, B. P. 2009. The Environmental Food Crisis: The Environment's Role in Averting Future Food Crises. A UNEP Rapid Response Assessment, United Nations Environment Programme, GRID-Arendal.

[3] FAO. 1996. "Food, Agriculture and Food Security: Developments Since the World Food Conference and Prospects.” Presented at World Food Summit, November 13-17, 1996, Rome.

[4] FAO. 2008. Expert Meeting on Global Perspectives on Fuel and Food Security: Technical Report.

[5] FAO. 2010. "Climate-Smart Agriculture: Policies and Financing for Food Security, Adaptation and Mitigation.” Accessed October 16, 2015. http://www.fao.org/docrep/013/i1881e/i1881e00.pdf.

[6] Du Toit, A., and Ziervogel, G. 2004. "Vulnerability and Food Insecurity: Background Concepts for Informing the Development of a National FIVIMS for South Africa.” Accessed October 9, 2015. http://www.agis.agric.za/agisweb/FIVIMS_ZA.html.

[7] International Labour Organization (ILO). 2007. "Employment by Sector." In Key Indicators of the Labour Market (KILM), 5th ed.. Genève: ILO.

[8] Gregory, P. J., Ingram, J. S. I., and Brklacich, M. 2005. “Climate Change and Food Security.” Philos. Trans. Roy. Soc. London B Biol. Sci. 360 (1463): 2139-48.

[9] IPCC. 2001. Climate Change 2001. Impacts, Adaptation and Vulnerability. Working Group 11 Contribution to the Intergovernmental Panel on Climate Change Third Assessment Report.

[10] Global Environment Facility (GEF). 2007. Status Report on the Climate Change Funds as of April 30, 2007. LDCF/SCCF, GEF, Washington, DC.

[11] UNFCCC. 2006. "The Nairobi Work Programme on 
Impacts, Vulnerability and Adaptation to Climate Change.” Accessed October 9, 2016. https://unfccc.int/files/adaptation/sbsta_agenda_item_ada ptation/application/pdf/nwp_brochure.pdf.

[12] FAO. 2007. Adaptation to Climate Change in Agriculture, Forestry and Fisheries: Perspective Framework and Priorities. Report of the FAO Interdepartmental Working Group on Climate Change, Rome.

[13] Schmidhuber, J., and Jubiello, F. N. 2007. "Global Food Security under Climate Change.” PNAS 104 (50): 19703-8.

[14] FAO. 2002. The State of Food Insecurity in the World 2001. Food and Agriculture Organization of the United Nations (FAO), Rome.

[15] Global Environmental Change and Food Systems (GECAFS). 2015. "Food System Activities.” Accessed October 12, 2015. http://www.gecafs.org/about/index.html.

[16] Ludi, E. 2009. Climate Change, Water and Food Security. Overseas Development Institute (ODI) Background Note, London.

[17] World Meteorological Organization (WMO). 1992. International Meteorological Vocabulary, 2nd ed.. Geneva: WMO.

[18] Shah, M., Fischer, G., and Van Velthuizen, H. 2008. Food Security and Sustainable Agriculture: The Challenges of Climate Change in Sub-Saharan Africa. Laxenburg: International Institute for Applied Systems Analysis.

[19] FAO/NRCB. 2008. "Climate Change and Food Security." Presented at the International Conference on Food Security and Environmental Change, April 2-4, 2008, Oxford, UK.

[20] Oxfam. 2007. "Weather Disasters Getting Worse.” BBC. Accessed October 14, 2015. http://www.bbc.con.uk/.

[21] Stamoulis, K., and Zezza, A. 2003. "Conceptual Framework for National, Agricultural, Rural Development, and Food Security Strategies and Policies.” ESA Working Paper No. 03-17, FAO. Accessed October 14, 2015. http://www.fao.org/docrep/007/ae050e/ ae050e00.htm.

[22] Devereux, S., and Maxwell, S., ed.. 2001. Food Security in Sub-Saharan Africa. Brighton, UK: Institute of Development Studies (IDS).

[23] Porter, J. R., and Semenov, M. A. 2005. "Crop Responses to Climatic Variation.” Philos. Trans. Roy. Soc London B Biol. Sci. 360 (1463): 2021-35.

[24] Wheeler, T. R., Crauford, P. Q., Ellis, R. H., Porter, J. R., and Vara Prasad, P. V. 2000. "Temperature Variability and the Yield of Annual Crops.” Agriculture, Ecosystems and Environment 82: 159-67.

[25] IPCC. 2007. Climate Change 2007-The Physical
Science Basis. Contribution of Working Group One to the Fourth Assessment Report of IPCC, Cambridge, UK.

[26] Gleick, P. H. 1993. Water in Crisis: A Guide to the World's Fresh Water Resources. New York: Oxford University Press.

[27] FAO. 2003. World Agriculture: Toward 2015/2030. Rome: Earthscan.

[28] World Bank Poverty Net. 2008. "Measuring Poverty.” Accessed Oct. 2015. hhtp://go.worldbank.org/VCBLGGE250.

[29] FAO. 1984. "Livestock Losses and Post Drought Rehabilitation in Sub-Saharan Africa.” Accessed October 17, 2015. http://www.fao.org/wairdocs/ILRI/x5439E/ x5439e02.htm.

[30] Toulmin, S. 1968. "The Limit of Allegiance in Nuclear Age.” In Nuclear Weapon and Future of Humanity, edited by Cohen, A., and Lee, S. Totowa, New Jersey: Rowman \& Littlefield Pub Inc., 357-9.

[31] Coppock, D. L. 1994. The Borana Plateau of Southern Ethiopia: Synthesis of Pastoral Research, Development and Change, 1980-91. Systems Study No. 5, International Livestock Center for Africa, Addis Ababa, Ethiopia.

[32] Barton, D., and Morton, J. 2001. "Livestock Marketing and Drought Mitigation in Northern Kenya." In Pastoralism, Drought and Planning: Lessons from Northern Kenya and Elsewhere, edited by Morton, J. Chatham, UK: Natural Resources Institute (NRI).

[33] Desta, S., and Coppock, D. L. 2002. "Cattle Population Dynamics in the Southern Ethiopian Rangelands, 1980-97.” Journal of Range Management 55: 439-51.

[34] Devereux, S., and Tapscott, C. 1995. "Coping Mechanisms of Communal Farmers in Response to Drought.” In Coping with Aridity: Drought Impacts and Preparedness in Namibia-Experiences from 1992/93, edited by Moorsom, R., Franz, J., and Mupotola, M. Frankfurt and Windhoek: Brandes and Apsel/NEPRU.

[35] Ndikumana, J., Stuth, J., Kamidi, R., Ossiya, S., Marambii, R., and Hamlett, P. 2000. Copping Mechanism and Their Efficacy in Disaster-Prone Pastoral Systems of the Greater Horn of Africa: Effects of the 1995-1997 Drought and the 1997-1998 El Nino Rains Responses of Pastoralist and Livestock. Nairobi, Kenya: International Livestock Research Institute.

[36] Kunreuther, H. C., and Michel-Kerjan, E. O. 2006. "Climate Change, Insurability of Large Scale Disasters and the Emerging Liability Challenge.” Presented at the University of Pennsylvania Law Conference on Climate Change, November 16-17, 2006, Philadelphia, USA.

[37] World Economic Forum. 2007. Global Risk Network Report.

[38] Hamilton, K. 2004. "Insurance and Financial Sector Support for Adaptation.” IDS Bulletin 35 (3): 55-61. 